\title{
What the Scientist Expects of the Librarian
}

$\mathrm{B}$ ASICALLY, the scientist expects adequate, efficient, and courteous service from the librarian. In these essential respects the wants of the scientist are much like those of anyone who uses a library. However, a scientist has some special needs. These requirements vary somewhat with the kind of library and the branch of science.

There are three main classes of libraries: (1) the city or town public library; (2) the college library; and (3) the specialized libraries associated with a university or a research institute or an industrial company. The clientele of public libraries does not usually include scientists who hope to obtain from such libraries access to special source material of the kind found in current science periodicals, comprehensive encyclopedias, and the like. If a public library is particularly strong in the field of science, then it may be said to fall in the category of a college or more highly specialized library.

In a college library the librarian or librarians

(I) Should have thorough familiarity with: indexing systems; logical and convenient arrangement of books; interlibrary loans; photostating and microfilm problems; the publishing habits of domestic and foreign periodicals so that such journals can be kept up-to-date and in good order; sources of manuscripts, reprints, patents, etc.

(2) Should keep abreast of publishers' announcements and book reviews, assume the initiative in taking up new purchases with the faculty. instead of waiting for them to make suggestions, and prepare regular bulletins to inform the clientele of new additions

(3) Should be capable of reading German, French, and Russian

(4) Should have sufficient scientific background to know technical language and nomenclature

(5) Should not only know where his books are at all times but should also know how to supplement catalog information with suggestions of likely places and people capable of supplying information not conventionally accessible. In addition to knowing where his books are he should help his patrons by guiding and instructing them in one manner or another to locate quickly and confidently material without too much trial and error. The departmental librarian can be of great help in assisting with or actually giving a course on the use of the literature of the particular discipline, and in this connection he should know something of the history of science.

Perhaps the greatest challenge and responsibility of a librarian comes in handling the needs of a specialized collection where scientific research is active. Progressive industrial laboratories present a striking illustration of the important services provided by a librarian. Partly because of the appreciation by industry of what a good librarian can do, and more so because of an adequate budget, the role of a librarian in industry is generally unlike that of librarians elsewhere. Such a librarian is frequently expected to make bibliographic or literature surveys on new research projects; to write up a good report on such topics; to make patent surveys and to examine pertinent patents for interference; to 
circulate current issues of periodicals to research workers, sometimes designating articles of particular significance in some segment of research; to have in addition to specialized knowledge some general knowledge to bridge disciplines; to gather material to be used in addresses and to assist in translations and the preparation of manuscripts; to avoid feeling wounded by an overdeveloped efficiency consciousness if some of his treasures are only nibbled at; to provide a medium or atmosphere for creative thought by the use of all accessible mechanical aids, even at the risk of pampering some indolent individuals; to aid in the syntheses of thoughts and ideas of the scientist by application of the intuitive sense which some librarians have of finding or suggesting things that are beyond the immediately available literature sources; and to do everything reasonable to supplement the overtaxed and limited memory of the scientist. All this does not mean that the scientist expects the librarian to know everything which he himself does not know.

The scientist in a university or research institute that is not strictly industrial cannot, at this time, expect all such services. His time is presumably not so valuable or not understood to be so valuable or there just is not the money (with a few exceptions) to implement such services. There is another reason for not having some of the services given by industrial libraries: some scientists feel, largely because of tradition, that there is no wholly adequate substitute for being their own research survey librarians. While it is true that many research ideas and fundamental correlations come from personal surveys, it is also true that the nonindustrial research scientist can profit by such services. The busy research worker in an actively growing field could be helped to overcome the drain on his energy and time by profiting from orienting surveys made for him. He would not lose the stimulation of selected readings in the original and would very probably use his more creative talents to a fuller extent. A development of this kind would surely be accelerated if more money were available to provide what are now considered to be special services outside of the industries.

Irrespective of the type of library and of the varied interests of scientists in different disciplines, the services which have been mentioned are now orthodox in their respective categories. Items like interlibrary loans, photocopying, microfilms, translations, and literature surveys are commonplace. What new services will the scientist expect of the librarian? The almost certain rapid and perhaps phenomenal growth of scientific literature in the years ahead is bound to bring with it devices to keep the alert scientist from being swamped. He will not sit by idly, content to be squeezed in a contracting area of his specialty. He has become increasingly aware of the importance of emerging from a restricted field to collateral and borderline zones, the entry to which has already paid rich dividends and promises high rewards in scientific achievement.

\section{New Tools Needed}

What he needs, particularly, are new tools to assist in the collection and integration of the growing mass of information. One device which is passing the formative stage is the system of punch cards. Already this is being put to practical use in several ways. One such application is by the Chemical-Biological Coordination Center, established by the National Research Council. The aim of this project is to provide a file on the hundreds of thousands of compounds so that one can quickly correlate chemical, physical, and biological properties. Undoubtedly, extensions of the punch card 
system will find applications in libraries for services like the rapid assembly and classification of bibliographic material.

Another highly suggestive tool or machine has been considered by Bush, ${ }^{1}$ for which the name "memex" was coined. "A memex is a device in which an individual stores all his books, records, and communications, and which is mechanized so that it may be consulted with exceeding speed and flexibility. It is an enlarged intimate supplement to his memory." This highly ingenious arrangement is essentially a desk in which can be conveniently stored by microfilm and other means the widest collection of books, photographs, and memoranda of all sorts. By appropriate currently available mechanisms and future electronic devices or patterns not pictured today, one might be able to assemble very promptly all co-related material in forms that can be seen or heard. This associative indexing of masses of material not only reduces drudgery by quickly providing relevant information but spares the mind of repetitive thought and provides an increasing opportunity for mature creative thought. A relatively simple extension of the idea would provide machines for manifold uses in libraries. The device is not at a blueprint stage, but it appears to be not only feasible but also not too costly.

By small increments of speculation one might arrive at developments which would change appreciably the present functions of libraries. For example, it is conceivable that the physicist and engineer might perfect deyices which would make it unnecessary to go to a library to obtain the information contained in the library. By suitable receiving sets, both visual and auditory in nature, the scientist might get directly in his laboratory, office, or elsewhere, all the information to be contained in libraries,

1 Bush, Vannevar. "As We May Think." Atlantic Monthly 176:101-08, July 1945 . whether it be from books, punch card data, correlative information by memex devices, or other aids as yet unformulated.

\section{Scientist's Greatest Needs}

All of these developments, irrespective of their being real or imaginary, point the way to the scientist's greatest needs. He wants to be liberated from the increasing drudgery of literature searching; he wants a means of keeping abreast with the great flow of information; he wants the use of all reasonable instruments which will assist him in correlating great masses of data and ideas so that he might once again be at home in the vast and important and overlapping areas of knowledge.

However, the scholar may obtain additional help without waiting for the millennium. Many persons in a variety of disciplines, some working in libraries and others in laboratories, who were consulted in the preparation of this article, feel that much more can be done now with currently available facilities. Two principles require especial emphasis: first, a librarian is more than a custodian of books; second, a library is more than a depository of books. First and foremost, these persons want books and periodicals made more accessible physically. With some groups of scientists, such as chemists, this means thoroughly adequate departmental libraries. A chemical library is like a laboratory to a chemist, and to work effectively he must have his books, like his chemicals and apparatus, housed in the same building with him. This is the procedure followed generally wherever real and substantial chemical research is done.

To be sure, there are some fine points on the limits of departmental libraries for all sciences. However, if adequate funds were available to buy $\mathrm{two}^{2}$ or more copies of

2 In this connection it is of interest to note that some industrial libraries have found it desirable to take two copies of periodicals, one of which remains in the library while the other circulates. 
books there is probably little doubt that all scientists would eagerly welcome departmental libraries. This ideal situation is, unfortunately, restricted at this time to a relatively small number of progressive and scholarly-outstanding institutions which have found the means to render such services. Other institutions of merit are or should be doing everything reasonable, within budgetary limitations, to provide duplication of material. What is needed, in some cases, is a well-crystallized philosophy that is oriented to provide the scholar with an increase of such facilities. With this should go a willingness and determination and aggressiveness on the part of the librarian to obtain more funds to help the scientist in his library needs.

We have mentioned some things which the scientist expects of the librarian. It might have been better to have written on what the scientist has a right to expect of the librarian. Competent librarians in active research groups must have special training and talents and they should have compensation commensurate with the great importance and dignity of their work. This compensation should be not only in terms of money but also in rank and prestige. The scientist has not fully appreciated the extent to which good teamwork with a librarian will advance research. 